\title{
La gastronomía como punto de encuentro entre lenguas y culturas ${ }^{*}$
}

\author{
Ma Elena Baynat Monreal \\ Universitat de València \\ Melena.baynat@uv.es \\ ORCID: 0000-0003-0956-0574
}

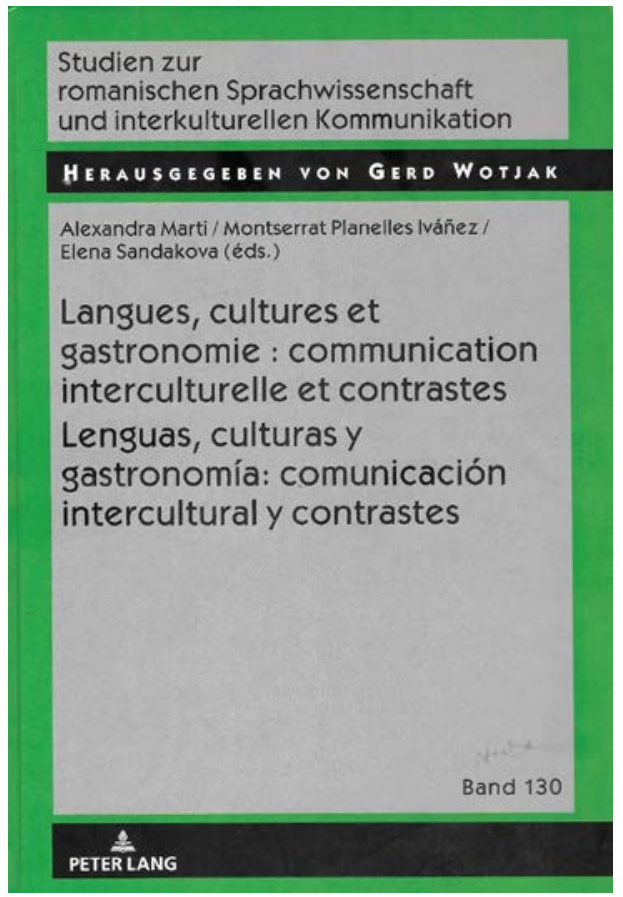

Presentamos un interesante libro centrado en el estudio de la lengua desde una perspectiva multicultural, concretamente, en relación con el tema de la gastronomía. En él se analizan la cocina y la alimentación como medios de transmisión de aspectos socioculturales inherentes a la lengua, lo que se viene a llamar "la gastronomía intercultural". Se considera que los usos y costumbres culinarios son un elemento esencial a la hora de estudiar y comprender las diversas identidades, es decir que constituyen un punto de encuentro entre las diferentes culturas y, en consecuencia, deben ser tenidos en cuenta para aprender y comprender cualquier idioma.

A través de los diferentes capítulos sus autores pivotan alrededor de tres vértices (lengua, cultura y gastronomía): génesis del título y materia esencial del volumen. Todo ello sin perder nunca de vista el objetivo didáctico, es decir, los beneficios que dicha combinación aporta al aprendizaje de

\footnotetext{
* A propósito de la obra editada por Alexandra Marti, Montserrat Planelles Iváñez y Elena Sandakova, Langues, culture et gastronomie: communication interculturelle et contrastes/Lenguas, cultura $y$ gastronomí: comunicación intercultural y contrastes (Berlín, Peter Lang, col. "Studien zur romanischen Sprachwissenschaft und interkulturellen Kommunikation”, 2018, 263 pp. ISBN: 978-84-6084-7984).
} 
lenguas. Sin embargo, podríamos decir que el eje vertebrador del volumen, el vértice principal en el que se apoyan los otros dos, es la gastronomía. Consideramos que es un gran acierto, puesto que dicho campo semántico ofrece una riqueza léxica excepcional en todos los idiomas y, además, requiere de la dimensión sociocultural para su total comprensión.

El primer bloque temático versa sobre aspectos teóricos e históricos de la comunicación intercultural en relación con la alimentación y la restauración.

En primer lugar, Montserrat Planelles, en su contribución titulada "Cultura, comunicación intercultural y gastronomía” realiza un recorrido histórico del significado de cultura que le lleva a definir y analizar conceptos teóricos como la multiculturalidad, la interculturalidad y el diálogo intercultural, todo ello con el fin de analizar la temática de la gastronomía como referente mundial, clave del conocimiento y la comprensión entre los diferentes pueblos. Finaliza afirmando que la comida y la cocina propician la diferenciación de los pueblos, entendida como un aspecto positivo enfocado hacia el descubrimiento del otro como disfrute y, en definitiva, el acercamiento a los demás a través de la comprensión y el diálogo.

Seguidamente, Pedro Nuño de la Rosa, en "Historia e interculturalidad en la cocina mediterránea" trata el asunto de la alimentación en relación con la cultura, explicando que sus orígenes están interrelacionados. Sin embargo, observa que no hay escritos de cocineros de la antigüedad que den testimonio de ello. Afirma que hay que esperar al siglo XIX para hallar indicios escritos de que se trate la cocina como cultura y como ciencia. Destaca la inevitable diferenciación histórica entre ricos y pobres en lo que se refiere a la gastronomía y el dominio e influencia culinaria de los pueblos invasores o colonizadores sobre los invadidos o colonizados. Finalmente, se centra en los conceptos de globalización e interculturalidad en el Mediterráneo.

En el siguiente capítulo, Natalia Khalina y Elena Sandakova nos presentan los restaurantes de quesos franceses e italianos de Barnaoul (Rusia). Comienzan con una introducción teórica sobre la filosofía de la comida, incidiendo también en el tema de la globalización alimentaria actual. Posteriormente, dichas autoras presentan la tradición quesera rusa puesto que, como comentan, el queso de esta zona es considerado un producto de lujo muy apreciado por la calidad de la leche utilizada para su elaboración. Añaden que, gracias a esta circunstancia, se ha establecido un interesante diálogo e intercambio técnico con otras naciones productoras de este alimento que ha culminado en la apertura en Siberia de varios restaurantes europeos de quesos de influencia francesa e italiana. Todo ello evidencia la importancia de la interacción entre países en lo que se refiere a la gastronomía y del desarrollo las nuevas tendencias culinarias - la llamada cocina fusión- que conjugan tradiciones locales e influencias extranjeras.

El segundo bloque temático de este interesante y jugoso libro se centra en aspectos lingüísticos, semióticos e interculturales relacionados con la gastronomía. 
Marina Aragón, en su capítulo titulado "Les expressions figées des légumes en disent long en français et en espagnol" describe con detalle un gran número de expresiones del argot común en lengua francesa y española relacionadas, todas ellas, con el universo metafórico de las verduras. Realiza una interesante clasificación de dicho léxico que ella misma califica de incompleta pero que es realmente muy amplia y detallada. En esta investigación se demuestra la gran riqueza de dicho campo semántico que da pie a la creación de expresiones hechas de todo tipo utilizadas en los más diversos contextos. La autora finaliza destacando el aspecto lúdico de las lenguas, principalmente en relación con los defectos humanos, motivo frecuente de burla o diversión que, como se observa en este capítulo, origina la creación de combinaciones léxicas muy ocurrentes.

Volvemos a Rusia de la mano de Elena Sandakova que en el capítulo titulado "stéréotypes au noyau "russe" portant sur les manifestations gastronomiques (en français et en espagnol)" analiza los estereotipos de franceses y espańoles en relación con la alimentación rusa. Tras una introducción teórica sobre los clichés, incidiendo en las causas de su formación y en sus funciones, la autora nos ofrece un análisis lingüístico-cultural del corpus seleccionado que contiene expresiones culinarias compuestas por un sustantivo o un verbo seguido del adjetivo "ruso"; como por ejemplo: "ensaladilla rusa”, "caviar ruso", "filete ruso", "té a la rusa”, "beber a la rusa”, etc. Demuestra así que existe un diálogo entre las dos culturas gastronómicas que origina la creación de ideas preconcebidas alejadas de la realidad, prueba evidente de que falta una mayor comunicación e interacción real entre los pueblos en vistas a clarificar muchos de estos falsos tópicos y de evitar los prejuicios y los malentendidos.

En "Expresión del maridaje y la conservación en el etiquetado del vino riojano y bordelés: similitudes y diferencias" Monserrat Planelles estudia otro elemento inherente a la gastronomía como es el vino y resalta la relevancia de la información que aparece en su etiquetado. La autora realiza un análisis comparativo entre la cultura del vino español (riojano) y francés (bordelés) partiendo de un corpus de etiquetas cuyos textos desmenuza, estudiando su contenido, principalmente en lo que respecta al maridaje y a la conservación del producto. Observa similitudes y diferencias de las costumbres vinícolas en ambos países y describe modas o tendencias que generan un nuevo tipo de turismo muy en boga -el enogastronómico- que, a su vez, da lugar al nuevo turista enológico o consumidor de vino, no muy diferente en ambos países. La autora descubre que las etiquetas españolas de vinos aportan más información que las francesas, hecho que revela que el consumidor hispano es menos experto en la materia que el galo y por ello demanda una mayor información sobre el producto que va a elegir y consumir.

Mercedes López Santiago nos habla en "La cocina molecular: estudio léxico e intercultural contrastico (español-francés)" de una de esta nueva tendencia culinaria del siglo XXI, analizando su gran desarrollo e internacionalización en los último años. 
Para esta investigación parte de un corpus lingüístico obtenido de documentos extraídos de páginas web de Internet que analiza desde una perspectiva contrastiva, realizando un estudio léxico y multicultural en español y en francés de esta novedosa moda culinaria. La autora clasifica el léxico de la cocina molecular reagrupándolo en varios bloques: ingredientes, técnicas, utensilios, presentación y denominación de los platos. Concluye que, aunque existen puntos de encuentro y coincidencias, este tipo de cocina varía según los países o pueblos que la incorporan a su cultura gastronómica, puesto que cada uno la adapta a sus realidades culturales. De modo que encontramos diversas variaciones en las recetas de los diferentes lugares que las realizan respecto a aspectos como puedan ser los ingredientes, las costumbres, las preparaciones, las denominaciones u otros.

Por su parte, Miguel Ávila en "El léxico culinario y de la alimentación en el dayra ceutí: la influencia hispánica y otras interferencias" examina el léxico culinario de esta lengua minoritaria así como sus interferencias con el castellano o los préstamos recibidos. El autor aborda el interesante fenómeno del bilingüismo en Ceuta, destacando que el dariya se utiliza mayormente en la lengua oral y el castellano en la escrita de lo que derivan conflictos de imitación lingüística así como una serie de interferencias, calcos y falsos amigos muy frecuentes. En este artículo presenta una muestra de especialidades de la gastronomía marroquí/musulmana de la zona y describe una serie de términos culinarios y de la alimentación en la lengua citada destacando su adaptación fonética y ortográfica al castellano con el que convive. Para terminar, afirma que el contacto entre ambos idiomas es cada vez mayor lo que deriva en una fosilización de los préstamos acrecentada por factores socioculturales (no meramente lingüísticos) como pueda ser la religión.

En el último capítulo de este bloque, titulado "El aporte visual de la etiqueta desde una perspectiva intercultural", Ricardo Sellers y Juan Luis Nicolau vuelven a aproximarse al tema del etiquetado del vino analizando aspectos visuales de sus etiquetas. Inciden en el hecho de la importancia que tienen, para la elección de un vino, ciertos aspectos de índole sociocultural como puedan ser la información que aparece en las etiquetas así como su embalaje, también destacan la necesidad de su adaptación a la cultura del consumidor. Concluyen que el mensaje escrito en ellas debe ser unitario y coherente además de conciso, puesto que debe adaptarse a un espacio reducido. Subrayan también la importancia de los lenguajes específicos y de los códigos visuales en este tipo de soporte (imágenes, arquitectura gráfica de las letras, colores, etc) así como la influencia de las tendencias o modas y la exportación vinícola que influyen en los mensajes escritos y visuales elegidos y, en última instancia, en la elección de un vino u otro.

El tercer y último bloque de esta apetitosa publicación se centra en aspectos relacionados con la didáctica de la lengua, siempre desde un punto de vista intercultural y centrado en la materia de la gastronomía. Se abordan contenidos relacionados 
con la alimentación que se consideran necesarios para trabajar en el aula de lengua extranjera con el fin de que los estudiantes comprendan el uso real de esta y la importancia de tener en cuenta, durante su aprendizaje, la dimensión sociocultural de los países donde se habla.

En el capítulo de Christian Leblond, "Du banquet français au repas d'affaires américain: une perspective interculturelle à l'usge des managers", se describen las diferentes costumbres y usos en la mesa entre diversas culturas, principalmente la francesa y la americana. Como explica el autor, la comida es la base sobre la que se sustenta el éxito de muchas negociaciones. Además, afirma que para triunfar en una comida de negocios se deben poseer ciertos conocimientos y capacidades que traspasan lo meramente lingüístico puesto que se basan en aspectos más amplios, como pueden ser son los diversos usos y costumbres en la mesa. Para demostrarlo analiza falsos amigos entre la lengua francesa e inglesa que no se limitan a meras diferencias léxicas sino que se precisan otros conocimientos culturales inherentes a ambas lenguas para comprenderlos y usarlos adecuadamente. Finaliza afirmando que para conocer una lengua y su cultura hay que ir más allá de los estereotipos de modo que se consiga conocer realmente a ese otro con el que se interactúa.

En "Quand les idiotismes gastronomiques s'invitent à la table d'un enseignement interculturel en clase de FLE en Espagne" Alexandra Marti analiza diversas expresiones idiomáticas o idiotismos gastronómicos que pueden ser utilizados para la enseńanza del francés como lengua extranjera. Son expresiones que no pueden ser traducidas literalmente y para las cuales es necesario encontrar equivalentes en el otro idioma que expresen ideas análogas. Según afirma la autora, los aprendices deberían conocer este tipo de vocabulario. Incide en la importancia de tener en cuenta los aspectos interculturales -incluido el aprendizaje de idiotismos- cuando se enseña otra lengua y apuesta por el diálogo multicultural en el aula para favorecer el plurilingüismo. Estudia diversos idiotismos gastronómicos frecuentes en francés relacionados con los alimentos primarios, realiza algunas propuestas didácticas para trabajarlos en clase y termina animando a los docentes a enseñar este tipo de vocabulario que ayuda a los aprendices a comprender mejor la lengua estudiada.

Por su parte, María Teresa del Olmo en "Perspectiva muticultural y multilingística en la didáctica de la Lengua y de la Literatura a través del ámbito de la alimentación en los libros de Miroslav Sasek" describe recursos literarios centrados en la alimentación susceptibles de ser utilizados con fines didácticos, concretamente los libros de ciudades de dicho autor, álbumes ilustrados que favorecen el estudio de las diferentes culturas, lenguas y sociedades desde una perspectiva de integración y que, a pesar de su apariencia infantil, según la autora, son de gran utilidad para aprender lengua y literatura así como para desarrollar la competencia comunicativa en entornos educativos de niveles educativos superiores. Dichos volúmenes, en cuanto al asunto que nos ocupa, se centran en el comportamiento social e individual de la alimenta- 
ción. Del Olmo destaca el carácter globalista, integrador, multicultural y multilingüístico de esta herramienta didáctica que considera muy útil para aprender lenguas sin perder de vista la cultura.

Finalmente, en "Tour de France des vins et fromages: convivialité et velouté du palais" Christine Verna realiza un recorrido léxico a través de los vinos y quesos franceses analizando sus más frecuentes combinaciones y combinatorias. Siguiendo la línea de otros autores citados, la autora considera que para comprender una lengua es fundamental tener en cuenta el conocimiento de aspectos culturales de la lengua aprendida, como por ejemplo, el arte de la necesaria combinación entre vinos y quesos. Analiza diversas expresiones usuales relacionadas con el gusto, el placer de la mesa y la convivialidad, desde sus orígenes hasta la actualidad. Realiza, asimismo, un tour de Francia de vinos y quesos. Verna considera que aprender es una actividad placentera que incluye el gusto por la rememorización. Termina el capítulo recordando que, además de ser necesario para aprender lenguas, el conocimiento socio-cultural es fundamental para comprender el mundo.

Resumiendo, la gastronomía es, como se afirma en la introducción del libro, un punto de encuentro entre las culturas, es decir, un suplemento de la cultura que influye en el conocimiento y/o aprendizaje de las lenguas favoreciendo, además, la eliminación de prejuicios o barreras interculturales y que facilita el diálogo, el conocimiento, la comprensión global y el acercamiento entre los pueblos. 